\title{
Curing of Epoxy Matrix Composites
}

\author{
ALFRED C. LOOS AND GeORGE S. SPRINGER \\ Department of Mechanical Engineering and Applied Mechanics \\ The University of Michigan, Ann Arbor, Michigan 48109
}

(Received October 19, 1982)

\begin{abstract}
Models were developed which describe the curing process of composites constructed from continuous fiber-reinforced, thermosetting resin matrix prepreg materials. On the basis of the models, a computer code was developed, which for flat-plate composites cured by a specified cure cycle, provides the temperature distribution, the degree of cure of the resin, the resin viscosity inside the composite, the void sizes, the temperatures and pressures inside voids, and the residual stress distribution after the cure. In addition, the computer code can be used to determine the amount of resin flow out of the composite and the resin content of the composite and the bleeder. Tests were performed measuring the temperature distribution in and the resin flow out of composites constructed from Hercules AS/3501-6 graphite epoxy prepreg tape. The data were compared with results calculated with the computer code for the conditions employed in the tests and good agreement was found between the data and the results of the computer code. A parametric study was also performed to illustrate how the model and the associated computer code can be used to determine the appropriate cure cycle for a given application, which results in a composite that is cured uniformly, has a low void content, and is cured in the shortest amount of time.
\end{abstract}

\section{INTRODUCTION}

C OMPOSITE PARTS AND STRUCTURES CONSTRUCTED FROM CONTINUOUS fiber reinforced thermosetting resin matrix prepreg materials are manufactured by arranging the uncured fiber resin mixture into the desired shape and then curing the material. The curing process is accomplished by exposing the material to elevated temperatures and pressures for a predetermined length of time. The elevated temperatures applied during the cure provide the heat required for initiating and maintaining the chemical reactions in the resin which cause the desired changes in the molecular structure. The applied pressure provides the force needed to squeeze excess resin out of the material, to consolidate individual plies, and to compress vapor bubbles.

The elevated temperatures and pressures to which the material is subjected are referred to as the cure temperature and the cure pressure. The magnitudes and durations of the temperatures and pressures applied during the curing process (denoted as the cure cycle) significantly affect the performance of the finished product. Therefore, the cure cycle must be selected carefully for each 
application. Some major considerations in selecting the proper cure cycle for a given composite material are:

a) the temperature inside the material must not exceed a preset maximum value at any time during cure,

b) at the end of cure, all the excess resin is squeezed out from every ply of the composite and the resin distribution is uniform,

c) the material is cured uniformly and completely,

d) the cured composite has the lowest possible void content, and

e) the curing process is achieved in the shortest amount of time.

At the present time, the cure cycle is generally selected empirically by curing small specimens and by evaluating the "quality" of the specimens after cure. Such empirical methods have several drawbacks; a) an extensive experimental program is usually required to determine the proper cure cycle for a given material, b) a cure cycle found to be satisfactory for a given material under one set of conditions may not apply under a different set of conditions, and c) they do not ensure that the composite was cured completely in the shortest amount of time.

The shortcomings of empirical approaches could be overcome by use of analytical models. Models applicable to different aspects of the curing process have been proposed by Springer and Loos [1-3]. In this paper, first the different models are extended and combined into a comprehensive model which relates the cure cycle to the thermal, chemical, and physical processes occurring in continuous fiber-reinforced composites during cure, and which then can be used to establish the most appropriate cure cycle in any given application. Second, the results of the model are compared to test data to verify the validity of the model. Third, it is shown how the model can be used to establish the cure cycle which results in a part that is cured uniformly, has a low void content, and is cured in the shortest time.

\section{MODEL}

In this section, a model is described which yields the following parameters during cure:

a) the temperature inside the composite as a function of position and time;

b) the pressure inside the composite as a function of position and time;

c) the degree of cure of the resin as a function of position and time;

d) the resin viscosity as a function of position and time;

e) the number of compacted prepreg plies as a function of time;

f) the amount of resin in the bleeder as a function of time;

g) the thickness and the mass of the composite as a function of time;

h) the void sizes, and the pressures and temperatures inside voids as functions of void locations and time; and

i) the residual stresses in each ply after cure.

A model providing the above-mentioned information is developed below in four parts. The first part of the model, referred to as the "thermo-chemical 
model," yields the temperature, the degree of cure, and the viscosity. The second part ("flow model") gives the pressure, the resin flow out of the composite, and the resin content of the composite and the bleeder. The third part ("void model") gives the void size and the temperature and pressure inside the void. The fourth part ("stress model") yields the residual stresses. Details of the models are presented subsequently. First, a brief description of the problem is given.

\section{Problem Statement}

We consider a fiber-reinforced epoxy matrix composite of initial thickness $L_{i}$ constructed from unidirectional continuous fiber "prepreg" tape (Figure 1). An absorbent material (referred to as a "bleeder") is placed on one side (or on both sides) of the composite. The thickness of the bleeder is $L_{b}$. The composite-bleeder system is placed on a metal tool plate ready for processing. A sheet of nonporous teflon release cloth is placed between the composite and the tool plate, and a sheet of porous teflon release cloth is placed between the composite and the bleeder to prevent sticking. A metal plate is placed on top of the bleeder, and an air breather is added when curing is done in an autoclave. Restraints (called "dams") are also mounted around the prepreg to prevent lateral motion and to minimize resin flow parallel to the tool plate and through the edges. Finally, a plastic sheet ("vacuum bag") is placed around the entire assembly when vacuum is applied during the cure. Here, we are concerned only with the composite-bleeder system illustrated in Figure 2, because the additional components (vacuum bag, air breather, teflon sheets, etc.) have no direct effect on the model.

Initially (time $<0$ ), the resin is uncured and the bleeder contains no resin. Starting at time $t=0$, the composite-bleeder system is exposed to a known temperature $T_{o}$. The cure temperature $T_{o}$ may be the same or may be different on the two sides of the composite-bleeder system. At some time $t_{p}\left(t_{p} \geqslant 0\right)$, a known pressure $P_{o}$ is applied to the system. Both the cure

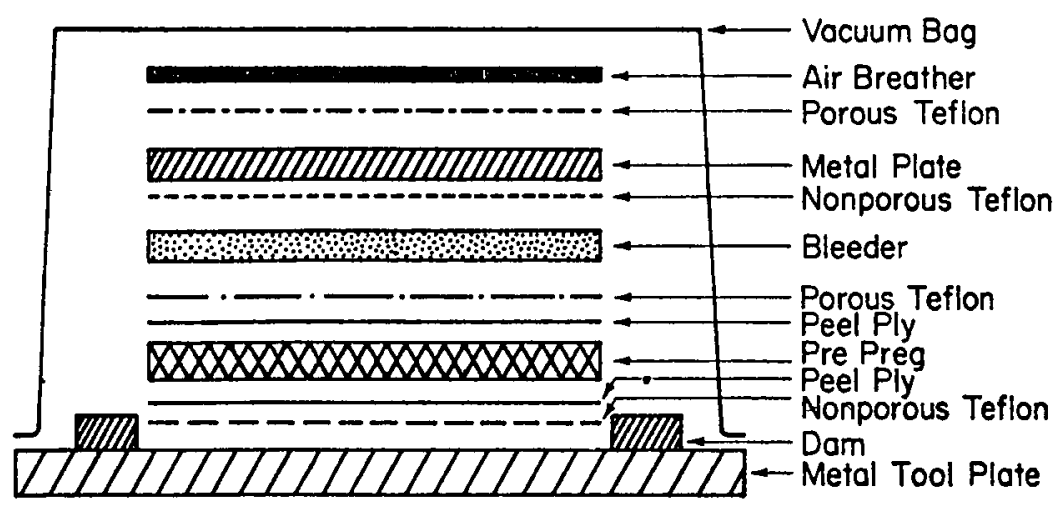

Figure 1. Schematic of the prepreg lay-up. 


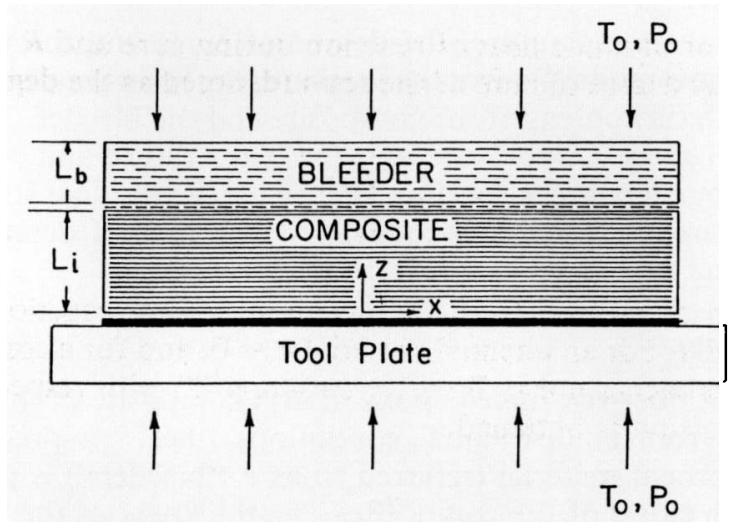

Figure 2. Geometry of the composite-bleeder system.

temperature $T_{o}$ and the cure pressure $P_{o}$ may vary with time in an arbitrary manner. The objective is to determine the parameters listed in points $a-i$ previously.

In formulating the model, resin is allowed to flow in the directions both perpendicular and parallel to the plane of the composite. Resin flow in the plane of the composite is allowed only in the direction parallel to the fibers. In order to emphasize the concepts and the solution methods, the properties in the plane of the composite are taken to be constant. However, the model and the method are general and can readily be extended to complex geometries. It is also noted that the analysis is presented for composites made of continuous fiber, unidirectional tape. The model can also be applied to composites made of woven fabric.

\section{Thermo-Chemical Model}

The temperature distribution, the degree of cure of the resin, and the resin viscosity inside the composite depend on the rate at which heat is transmitted from the environment into the material. The temperature inside the composite can be calculated using the law of conservation of energy together with an appropriate expression for the cure kinetics. By neglecting energy transfer by convection, the energy equation may be expressed as

$$
\frac{\partial(\varrho C T)}{\partial t}=\frac{\partial}{\partial z}\left(K \frac{\partial T}{\partial z}\right)+\varrho \dot{H}
$$

where $\varrho$ and $C$ are the density and specific heat of the composite, $K$ is the thermal conductivity in the direction perpendicular to the plane of the composite, and $T$ is the temperature. $\dot{H}$ is the rate of heat generated by chemical reactions and is defined in the following manner.

$$
\dot{H}=R H_{R}
$$


$H_{R}$ is the total or ultimate heat of reaction during cure and $R$ is the reaction or cure rate. The degree of cure of the resin (denoted as the degree of cure, $\alpha$ ) is defined as

$$
\alpha \equiv \frac{H(t)}{H_{R}}
$$

$H(t)$ is the heat evolved from the beginning of the reaction to some intermediate time, $t$. For an uncured material $\alpha=0$, and for a completely cured material, $\alpha$ approaches unity. By differentiating (3) with respect to time, the following expression is obtained.

$$
\dot{H}=\frac{d a}{d t} H_{R}
$$

A comparison of Eqs. (2) and (4) shows that, in this formulation, $d \alpha / d t$ is the reaction or cure rate. If diffusion of chemical species is neglected, the degree of cure at each point inside the material can be calculated once the cure rate is known in the following way

$$
\alpha=\int_{0}^{t}\left(\frac{d \alpha}{d t}\right) d t
$$

In order to complete the model, the dependence of the cure rate on the temperature and on the degree of cure must be known. This dependence may be expressed symbolically as

$$
\frac{d \alpha}{d t}=f(T, \alpha)
$$

The functional relationship in Eq. (6), along with the value of the heat of reaction $H_{R}$ for the prepreg material under consideration, can be determined experimentally by the procedures described in ref. [4].

The density $\varrho$, specific heat $C$, heat of reaction $H_{R}$, and thermal conductivity $K$ depend on the instantaneous, local resin and fiber contents of each ply. The properties $\varrho, C$, and $H_{R}$ can be calculated by the rule of mixtures [5]. The thermal conductivity of the prepreg can be calculated by the approximate formula developed by Springer and Tsai [6].

Solutions to Eqs. (1) and (4)-(6) can be obtained once the initial and boundary conditions are specified. The initial conditions require that the temperature and degree of cure inside the composite be given before the start of the cure (time $<0$ ). The boundary conditions require that the temperatures on the top and bottom surfaces of the composite be known as a function of time during cure (time $\geqslant 0$ ). Accordingly, the initial and boundary conditions corresponding to Eqs. (1) and (4)-(6) are 
Initial conditions:

$$
\left.\begin{array}{l}
T=T_{i}(z) \\
\alpha=0
\end{array}\right\} \begin{gathered}
0 \leqslant z \leqslant L \\
t<0
\end{gathered}
$$

$T_{i}$ is the initial temperature in the composite.

Boundary conditions:

$$
\left.\begin{array}{l}
T=T_{L}(t) \text { at } z=0 \\
T=T_{u}(t) \text { at } z=L
\end{array}\right\} t \geqslant 0
$$

where $T_{u}$ and $T_{L}$ are the temperatures on the top and bottom surfaces of the composite, respectively (Figure 3 ).

Solutions to Eqs. (1) and (4)-(8) yield the temperature $T$, the cure rate $d \alpha / d t$, and the degree of cure $\alpha$ as functions of position and time inside the composite.

Once these parameters are known, the resin viscosity can be calculated, provided a suitable expression relating resin viscosity to the temperature and degree of cure is available. If the resin viscosity is assumed to be independent of shear rate, then the relationship between viscosity, temperature, and degree of cure can be represented in the form

$$
\mu=g(T, \alpha)
$$

The manner in which the relationship between viscosity, temperature, and degree of cure can be established is described in ref. [4].

\section{Resin Flow Model}

At some time $t_{p}\left(t_{p} \geqslant 0\right)$, pressure is applied to the composite-bleeder system (Figure 3). As a result of this pressure, resin flows from the composite into the bleeders. Resin flow in the direction parallel to the plane of the composite

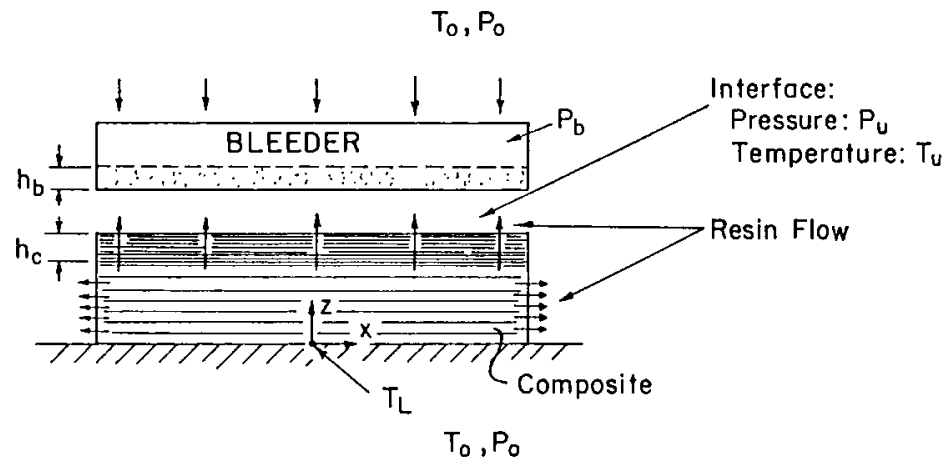

Figure 3. Resin flow model. 
can be neglected if a) both the width and the length of the composite are large compared to the thickness $L$, and b) if restraints are placed around the sides of the composite. This situation is generally encountered in practice. When modelling the curing process of systems where the aforementioned conditions are met, only resin flow normal to the tool plate need to be taken into account. However, under some conditions, resin flow along the fibers cannot be prevented. This situation may occur when the length of the composite is similar to the thickness. Under these circumstances, resin flow both normal and parallel to the tool plate takes place simultaneously. The model must then consider resin flow in both directions. In the model that is developed below, resin flow both normal and parallel to the tool plate is taken into account.

Before the resin flow model is established, the behavior of the prepreg plies during the squeezing action (cure pressure application) is examined.

The resin flow process normal to the tool plate was demonstrated by Springer [2] to occur by the following mechanism. As pressure is applied, the first (top) ply $\left(n_{s}=1\right.$, Figure 4$)$ moves toward the second ply $\left(n_{s}=2\right)$, while resin is squeezed out from the space between the plies. The resin seeps through the fiber bundles of the first ply. When the fibers in the first ply get close to the fibers in the second ply, the two plies move together toward the third ply, squeezing the resin out of the space between the second and the third ply. This sequence of events is repeated for the subsequent plies. Thus, the interaction of the fibers proceeds down the prepreg in a wavelike manner (Figure 4).

Note that there are essentially two regions in the composite. In region 1 , the plies are squeezed together and contain no excess resin, while in region 2 the plies have not moved and have the original resin content. Some compacting of the fibers within the individual plies may also occur but, as a first approximation, this effect is neglected here.

It is noted that there is a pressure drop only across those plies through which resin flow takes place. The pressure is constant (and equal to the applied pressure $P_{o}$ ) across the remaining layers of prepreg.

When there is resin flow in both the normal and parallel directions, resin is squeezed out from between every bly continuously, as long as there is excess
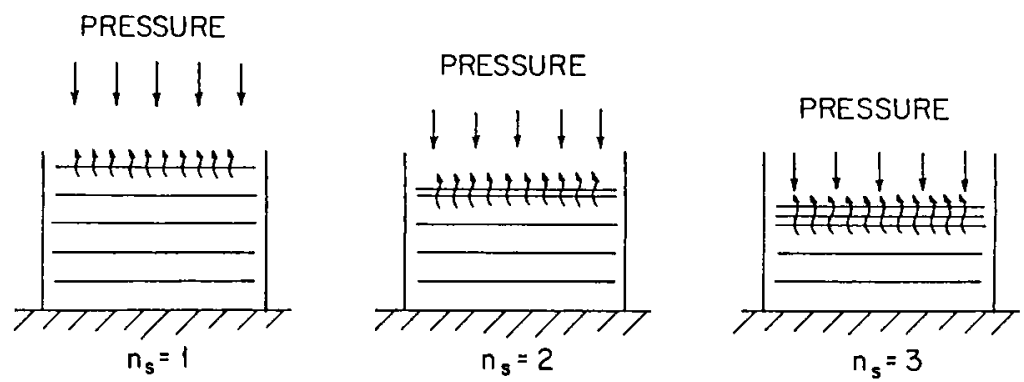

Figure 4. Illustration of the resin flow process normal to the tool plate. 
resin between adjacent plies. In this case, the thickness between different plies vary and change with time, as illustrated in Figure 5.

Although the resin flow in the normal and parallel directions are related, to facilitate the calculations in the model, the two phenomena are decoupled. Hence, separate models are described below for the resin flow in directions normal and parallel to the tool plate.

The model developed predicts changes in the dimensions of the composite only due to changes in the resin content. Shrinkage due to changes in the molecular structure of the resin during cure is not considered.

\section{Resin Flow Normal to the Tool Plate}

Owing to the complex geometry, the equations describing the resin flow through the composite normal to the tool plate ( $z$ direction) and into the bleeder cannot be established exactly. Nevertheless, an approximate formulation of the problem is feasible by treating the resin flow through both the composite and bleeder as flow through porous media. Such an approach was proposed by Bartlett [7] for studying resin flow through glass fabric prepreg, and by Loos and Springer [1-3] for resin flow in continuous fiber prepregs. In the model, inertia forces are considered to be negligible compared to viscous forces. Then, at any instant of time, the resin velocities in the prepreg and in the bleeder may be represented by Darcy's law

$$
V=-\frac{S}{\mu} \frac{d P}{d z}
$$

where $S$ is the apparent permeability, $\mu$ is the viscosity, and $d P / d z$ is the pressure gradient. The law of conservation of mass (together with Eq. 10) gives the following expression for the rate of change of mass $M$ in the composite

$$
\frac{d M}{d t}=-\varrho_{r} A_{z} V_{z}=-\varrho_{r} A_{z} S_{c} \frac{P_{c}-P_{u}}{\int_{o}^{h_{c}} \mu d z}
$$

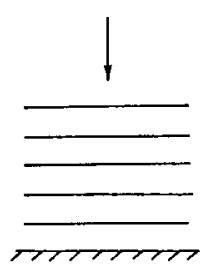

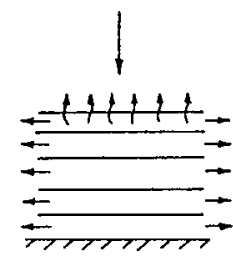

$n_{s}=1$

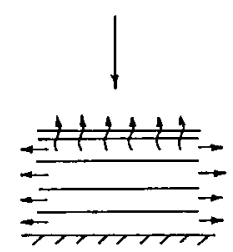

$n_{s}=2$

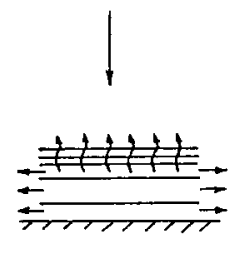

$n_{\mathrm{s}}=3$

Figure 5. Simultaneous resin flow both normal and parallel to the tool plate. 
where $\mathrm{Q}_{r}$ is the resin density, $A_{z}$ is the cross sectional area perpendicular to the $z$ axis, $h_{c}$ is the thickness of the compacted plies, i.e., the thickness of the layer through which resin flow takes place (Figure 3). $P_{u}$ is the pressure at the interface between the composite and the bleeder. The subscript $c$ refers to conditions in the composite at position $h_{c}$. Accordingly, $P_{c}$ is the pressure at $h_{c}$ and is the same as the applied pressure $\left(P_{c}=P_{o}\right)$ [2].

At any instant of time, the resin flow rate through the composite is equal to the resin flow rate into the bleeder

$$
\varrho_{r} A_{z} V_{z}=\varrho_{r} A_{z} V_{b}
$$

The temperature, and hence the viscosity, of the resin inside the bleeder is assumed to be independent of position (but not of time). Thus, Eqs. (10) and (12) yield

$$
\varrho_{r} A_{z} V_{z}=\varrho_{r} A_{z} \frac{S_{b}}{\mu_{b}} \frac{P_{u}-P_{b}}{h_{b}}
$$

where $h_{b}$ is the instantaneous depth of resin in the bleeder. The subscript $b$ refers to conditions in the bleeder. In developing the above expressions, the pressure drop across the porous teflon sheet between the bleeder and the composite was neglected.

Noting that the mass of the fibers in the composite remains constant, Eqs. (11)-(13) may be rearranged to yield the following expression for the rate of change of resin mass in the composite

$$
\frac{d M_{r}}{\mathrm{dt}}=\frac{-\mathrm{e}_{r} A_{z} S_{c}}{\int_{o}^{h_{c}} \mu d z}\left(\frac{P_{o}-P_{b}}{l+G(t)}\right)
$$

The parameter $G(t)$ is defined as

$$
G(t) \equiv \frac{S_{c}}{S_{b}} \frac{\mu_{b} h_{b}}{\int_{o}^{h_{c}} \mu d z}
$$

$M_{r}$ is the mass of resin in the composite at any instant of time. The mass of resin that leaves the composite and enters the bleeder in time $t$ is

$$
M_{T}=\int_{o}^{t} \frac{d M_{r}}{d t} d t
$$

The instantaneous resin depth in the bleeder is related to the mass of resin that enters the bleeder by the expression 


$$
h_{b}=\frac{1}{Q_{r} \phi_{b} A_{z}} \int_{o}^{t} \frac{d M_{r}}{d t} d t
$$

where $\phi_{b}$ is the porosity of the bleeder and represents the volume (per unit volume) which can be filled by resin. The thickness of the compacted plies is

$$
h_{c}=n_{s} h_{1}
$$

where $h_{1}$ is the thickness of one compacted prepreg ply and $n_{s}$ is the number of compacted prepreg plies. The value of $n_{s}$ varies with time, depending on the amount of resin that has been squeezed out of the composite.

Equations (11)-(18) are the relationships needed for calculating the resin flow normal to the tool plate.

\section{Resin Flow Parallel to the Tool Plate}

In principle, in the plane of the composite, resin may flow along the fibers and in the direction perpendicular to the fibers. In practice, resin flow perpendicular to the fibers is small because of a) the resistance created by the fibers and $b$ ) the restraints placed around the edges of the composite. If such restraints were not provided, fiber spreading ("wash out") would occur, resulting in a non-uniform distribution of fibers in the composite. Therefore, in this section, only resin flow along the fibers is considered.

It is assumed that resin flow along the fibers and parallel to the tool plate can be characterized as viscous flow between two parallel plates separated by a distance $d_{n}$ ("channel flow," Figure 6). The distance, $d_{n}$, separating the plates is small compared to the thickness of the composite $\left(d_{n}<L\right)$. The variation in resin properties across and along the channel are
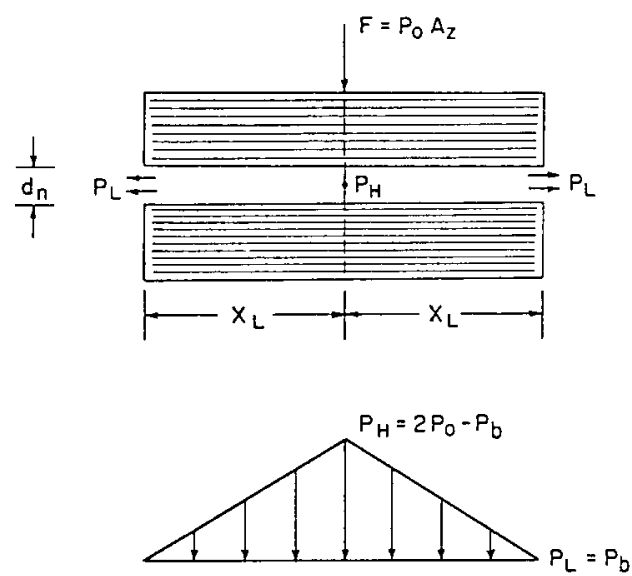

Figure 6. Geometry of the resin flow model parallel to the tool plate. 
taken to be constant. The pressure drop between the center of any given channel and the channel exit $\left(P_{H} \cong-P_{L}\right.$, Figure 6) can then be expressed as [8]

$$
\frac{2\left(P_{H}-P_{L}\right)}{\varrho_{r}\left(V_{x}^{2}\right)_{n}}=\lambda \frac{X_{L}}{d_{n}}
$$

where $\left(V_{x}\right)_{n}$ is the average resin velocity in the channel, $X_{L}$ is the channel length. The subscript $n$ refers to the channel located between the $n$ and $n-1$ prepreg plies (i.e., beneath the fiber bundles of prepreg ply $n$ ). The thickness of $n$th channel is calculated by assuming that a) there is one channel per ply and b) all the excess resin is contained in the channel. Accordingly, the thickness of the channel is given by the following expression:

$$
d_{n}=\frac{M_{n}}{\varrho_{n} A_{z}}-\frac{M_{\mathrm{com}}}{\varrho_{\mathrm{com}} A_{z}}
$$

The mass $M_{n}$ and density $\varrho_{n}$ of prepreg ply $n$ can be calculated by the rule of mixtures [5]. $M_{\text {com }}$ and $\varrho_{\text {com }}$ are the mass and the density of a compacted prepreg ply, respectively. The technique used to determine $M_{\text {com }}$ is described in the next section, along with an appropriate expression for determining $\varrho_{\text {com. }}$. For laminar flow between parallel plates, $\lambda$ is defined as

$$
\lambda \equiv \frac{(1 / B) \mu_{n}}{e_{r}\left(V_{x}\right)_{n} d_{n}}
$$

where $\mu_{n}$ is the viscosity of the resin in the channel. Substitution of Eq. (21) into Eq. (20) yields the following expression for the average velocity in the channel

$$
\left(V_{x}\right)_{n}-B{\underset{\mu_{n}}{d_{n}^{2}}}_{\frac{\left(P_{H}-P_{L}\right.}{X_{L}}}
$$

where $B$ is a constant which must be determined experimentally. The resin mass flow rate is

$$
\left(m_{r x}\right)_{\mathrm{n}}=\varrho_{r} A_{x}\left(V_{x}\right)_{n}
$$

where $A_{x}$ is the cross sectional area defined as the product of the channel width $W$ and thickness, $d_{n}$.

The law of conservation of mass, together with Eqs. (22)-(23), gives the following expression for the rate of change of mass in the $n$th prepreg ply

$$
\frac{d\left(M_{r}\right)_{\mathrm{n}}}{d t}=-2\left(m_{r x}\right)_{\mathrm{n}}=-2 B \frac{d_{n}^{3}}{\mu} e_{r} W \frac{\left(P_{H}-P_{L}\right)}{X_{L}}
$$


The amount of resin leaving the $n$th prepreg ply in time $t$ is

$$
\left(M_{E}\right)_{\mathrm{n}}=\int_{o}^{t} \frac{d\left(M_{r}\right)_{n}}{d t} d t
$$

The total amount of resin flow parallel to the tool plate can be determined by summing Eq. (25) over all plies containing excess resin

$$
M_{E}=\sum_{n=1}^{N-n_{s}}\left(M_{E}\right)_{n}
$$

where $N$ is the total number of prepreg plies.

The pressure at the centerline of the channel $P_{H}$ can be estimated from the force balance applied along the boundaries of the channel. Assuming that the pressure gradient in the $x$ direction is linear, and that the centerline pressure $P_{H}$ is the same in each ply, the pressure distribution of each channel may be expressed as

$$
P=\left(\frac{P_{L}-P_{H}}{X_{L}}\right) x+P_{H}
$$

where $P_{L}$ is the pressure at the exit of the channel and is assumed to be equal to the pressure of the environment surrounding the composite $P_{b}$. A force balance applied along the channel surface gives (Figure 6)

$$
F=\int_{A} P d A=2 W \int_{o}^{X_{L}} P d x
$$

$F$ is the applied force which can be related to the cure pressure $P_{o}$ as

$$
F=P_{o} A_{z}=2 P_{o} W X_{L}
$$

Equations (27)-(29) yield the centerline pressure

$$
P_{H}=2 P_{o}-P_{b}
$$

Equations (19)-(30) are the relationships needed for calculating the resin flow in the direction along the fibers.

\section{Total Resin Flow}

The total resin flow out of the composite in time $t$ is the sum of the resin flows both normal and parallel to the tool plate. The law of conservation of 
mass gives the following expression for the total rate of change of mass $M$ in the composite

$$
\frac{d M}{\mathrm{dt}}=-\left[\dot{m}_{r z}+2 \sum_{n=1}^{\mathrm{N}-n_{s}}\left(m_{r x}\right)_{n}\right]
$$

where $m_{r z}$ and $m_{r x}$ are the resin mass flow rates normal to the tool plate ( $z$ direction) and parallel to the tool plate ( $x$ direction), respectively.

The total mass of the composite at time $t$ is

$$
M=M_{i}-M_{T}-M_{E}
$$

where $M_{T}$ and $M_{E}$ are defined by Eqs. (16) and (26) and $M_{i}$ is the initial mass of the composite. The composite thickness at time $t$ is

$$
L=\frac{M}{\varrho 2 X_{L} W}
$$

where $\varrho$ is the density of the composite.

\section{Void Model}

Void nuclei may be formed either by mechanical means (e.g. air or gas bubble entrapment, broken fibers) or by homogeneous or heterogeneous nucleation [9]. Once a void is established, its size may change due to three effects: a) changes in vapor mass inside the void caused by vapor transfer through the void-prepreg interface, b) changes in pressure inside the void due to changes in temperature and pressure in the prepreg, and c) thermal expansion (or shrinking) due to temperature gradients in the resin. The model described below takes into account the first two of these effects, namely vapor transfer and changes in temperature and pressure.

A spherical nucleus of diameter $d_{i}$ is assumed to be at a given location in the prepreg. The nucleus is filled with water vapor resulting from the humid air surrounding the prepreg during lay-up. The partial pressure of the water vapor in the nucleus $\boldsymbol{P P} \boldsymbol{P}_{w i}$ is related to the relative humidity $\phi_{a}$ by the expression

$$
P P_{w i}=\phi_{a} P_{w g a}
$$

where $P_{w g a}$ is the saturation pressure of the water vapor at the ambient temperature. From the known values of the initial partial pressure $P P_{w i}$ and the initial nucleus volume, the initial mass $m_{w i}$ and the initial concentration $\left(c_{\nu w}\right)_{i}$ of the water vapor in the nucleus can be determined.

During the cure, the volume of the void changes because a) water and other types of molecules are transported across the void-prepreg interface, and 
b) the cure pressure increases the pressure at the location of the void. For a spherical void of diameter $d$, the total pressure inside the void $P_{v}$ is related to the pressure in the prepreg surrounding the 'void $P$ by the expression

$$
P_{v}-P=\frac{4 o}{d}
$$

$\sigma$ is the surface tension between the resin and the void. $P_{\nu}$ is the total pressure inside the void and is the sum of the partial pressures of the air and the different types of vapors present in the void. In the model outlined below, it is assumed that only water-vapor is transported through the void-prepreg interface. However, this assumption does not affect the formulation of the model. If necessary, other types of vapors can readily be included in the calculations, as described by Springer [1].

The pressure inside the void is

$$
P_{v}=P P_{w}+P P_{\text {air }}
$$

$P P_{w}$ and $P P_{\text {air }}$ are the partial pressures of the water vapor and the air in the void. The partial pressure is a known function of the temperature, mass, and the void diameter

$$
\begin{aligned}
P P_{\text {air }} & =f\left(T, m_{\text {air }}, d\right) \\
P P_{w} & =f\left(T, m_{w}, d\right)
\end{aligned}
$$

Thus, if the pressure in the prepreg around the void, the temperature inside the void (taken to be the same as the temperature of the prepreg at the void location), and the mass of vapor in the void are known, the partial pressure, the total pressure, and the void diameter can be calculated from Eqs. (35)-(37). The temperature and the pressure are given by the thermochemical-resin-flow models. The air mass in the void is taken to be constant. Thus, it remains to evaluate the mass of water vapor in the void as a function of time. The change in water vapor mass may be calculated by assuming that the vapor molecules are transported through the prepreg by Fickian diffusion. Fick's law gives

$$
\frac{d c}{d t}=D\left(\frac{\partial^{2} c}{\partial r^{2}}+\frac{2}{r} \frac{\partial c}{\partial r}\right)
$$

$c$ is the water vapor concentration at a radial coordinate $r$, with $r=0$ at the center of the void. $D$ is the diffusivity of the water vapor through the resin in the $r$ direction.

Initially $(t<0)$ the vapor is taken to be distributed uniformly in the prepreg at the known concentration $c$

$$
c=c_{i} \text { at } r \geqslant d_{i} / 2 \quad t<0
$$


At times $t \geqslant 0$ the vapor concentration at the void-prepreg interface must be specified. By denoting the concentration at the prepreg surface by the subscript $m$, we write

$$
\left.\begin{array}{l}
c=c_{m} \text { at } r=d / 2 \\
c=c_{i} \text { at } r \rightarrow \infty
\end{array}\right\} t \geqslant 0
$$

The second of the above expressions reflects the fact that the concentration remains unchanged at a distance far from the void. The surface concentration is related to the maximum saturation level $M_{m}$ in the prepreg by the expression

$$
c_{m}=\varrho M_{m}
$$

The value of $M_{m}$ can be determined experimentally for each vapor-resin system [10].

Solutions of Eqs. (38)-(41) yield the vapor concentration as a function of position and time $c=f(r, t)$. The mass of vapor transported in time $t$ through the surface of the void is

$$
m_{T}=-\int_{o}^{t} \pi d^{2} D\left(\frac{\partial c}{\partial r}\right)_{r=d / 2} d t
$$

The mass of vapor in the void at time $t$ is

$$
m=m_{i}-m_{T}
$$

The initial mass of water vapor in the void is known, as was discussed previously.

Solutions to Eqs. (34)-(43) give the void size and the pressure inside the void as functions of time, for a void of known location and initial size.

\section{Stress Model}

For a symmetric laminate, the residual stress in any given ply is [11]

$$
\sigma_{i}=Q_{i j}\left(e_{o j}-e_{j}\right)
$$

$Q_{i j}$ is the modulus as defined by Tsai and Hahn [11]. The strain $e_{j}$ is

$$
e_{j}=\alpha_{j}\left(T-T_{a}\right)
$$

where $\alpha_{j}$ is the thermal expansion coefficient, $T_{a}$ is the ambient temperature, and $T$ is the temperature in the ply at the end of the cure given by the thermochemical model. The laminate curing strain is 


$$
e_{o j}=a_{i j} \int_{o}^{L} Q_{i j} e_{j} d z
$$

$a_{i j}$ is the inplane compliance of a symmetric laminate as defined by Tsai and Hahn.

Solution of Eqs. (44)-(46) yield the residual stress in each ply.

\section{METHOD OF SOLUTION}

Solutions to the thermo-chemical, flow, void, and stress models must be obtained by numerical methods. A computer code (designated as "CURE") suitable for generating solutions was developed, and is available from the Department of Mechanical Engineering and Applied Mechanics, The University of Michigan.

Solutions of the model (and the corresponding computer code) require that the parameters listed in Tables 1 and 2 be specified. The parameters pertaining to the geometry, along with the initial and boundary conditions are specified by the user of the prepreg. The properties of the prepreg, the fiber, the resin, and the bleeder cloth are either specified by the manufacturer or can often be found in the published literature. Items (11) through (14) in Table 1 and item 8 in Table 2 are generally unknown. In the following, a brief description is given of the methods which can be used to determine these parameters.

The compacted prepreg ply thickness and the compacted prepreg ply resin content can be determined by constructing a thin ( 4 to 16 ply) composite panel. The panel is cured employing a cure cycle that will ensure that all the excess resin is squeezed out of every ply in the composite (i.e., all plies are consolidated $n_{s}=N$ ). The total mass of the composite $M$ is measured after cure. The resin content of one compacted prepreg ply $\left(M_{r}\right)_{\text {com }}$ is related to the composite mass by the expression

$$
\left(M_{r}\right)_{\mathrm{com}}=\frac{M}{N}-M_{f}
$$

$M_{f}$ is the fiber mass of one prepreg ply, and $N$ is the total number of plies in the composite. The compacted prepreg ply thickness $h_{1}$ is

$$
h_{1}=\frac{M / N}{\varrho_{\mathrm{com}} A_{z}}
$$

where $\varrho_{\text {com }}$ is compacted ply density which can be derived from the rule of mixtures [5].

The apparent permeability of the prepreg normal to the fibers $S_{c}$ can be determined by curing a thin ( 4 to 8 ply) composite specimen for a predetermined length of time. During the cure, the resin squeezed out through the 
Table 1. Input Parameters Required for Solutions of the Thermo-Chemical and Resin Flow Models.

A. Geometry

1) Length of the composite

2) Width of the composite

3) Number of plies in the composite

B. Initial and Boundary Conditions

4) Initial temperature distribution in the composite

5) Initial degree of cure of the resin in the composite

6) Cure temperature as a function of time

7) Cure pressure as a function of time

8) Pressure in the bleeder

C. Prepreg Properties

9) Initial thickness of one ply

10) Initial resin mass fraction

11) Resin content of one compacted ply

12) Compacted ply thickness

13) Apparent permeability of the prepreg normal to the plane of the composite

14) Flow coefficient of the prepreg parallel to the fibers

D. Resin Properties

15) Density

16) Specific heat

17) Thermal conductivity

18) Heat of reaction

19) Relationship between the cure rate, temperature, and degree of cure

20) Relationship between the viscosity, temperature, and degree of cure

E. Fiber Properties

21) Density

22) Specific heat

23) Thermal conductivity

F. Bleeder Properties

24) Apparent permeability

25) Porosity

Table 2. Input Parameters Requires in the Computer Code for Calculating Void Sizes. (These parameters are in addition to those in Table 1.)

\section{Void Model}

A. Initial and Boundary Conditions
1) Initial void size
2) Initial void location
3) Initial water vapor concentration in prepreg
4) Ambient relative humidity
5) Ambient temperature

B. Resin Properties

6) Expression relating the relative humidity to the maximum saturation level of water vapor in the resin

7) Diffusivity of water vapor through the resin

8) Surface tension at the resin-void interface 
Table 2 (continued)

\section{Streas Model}

A. Properties of the Composite

1) Longitudinal and transverse Young's moduli

2) Longitudinal and transverse Poisson's ratios

3) Longitudinal and transverse shear moduli

4) Longitudinal and transverse thermal expansion coefficients

B. Stacking Sequence

5) Orientation of each ply

C. Environment

6) Ambient temperature

plane of the composite normal to the tool plate is collected in the bleeder placed on the top of the composite. After the cure is terminated, the amount of resin in the bleeder (i.e., the resin flow into the bleeder) is determined by measuring the difference between the original bleeder weight (mass) and the final weight (mass) of the resin-soaked bleeder. An initial value for the apparent permeability is estimated, and the resin flow normal to the fibers is calculated using the flow model. The value of the permeability is adjusted and the calculations are repeated until the calculated and measured resin flows match.

The flow coefficient of the prepreg parallel to the fibers (B) can be estimated from the following procedure. A thick composite (approximately 30-60 ply thick) is cured for a predetermined length of time. Resin squeezed out from between the individual plies (parallel to the fibers) is collected by bleeders placed around the edges of the composite. The resin flow through the edges is determined by measuring the difference between the original weight of the "edge" bleeders and the final weight of the resin-soaked bleeders. Assuming a value for the flow coefficient, the resin flow parallel to the fibers is calculated using the flow model. The value of the flow coefficient is adjusted and the calculations are repeated until the measured resin flow matches the calculated resin flow.

The surface tension at the void resin interface may be approximated by the surface tension of water.

\section{VALIDATION OF THE MODEL}

Experiments were performed to verify two major aspects of the model, namely the thermo-chemical and resin flow models. The principles underlying the stress model have generally been accepted $[11,12]$ and, therefore, further verification was deemed unnecessary. Experimental evidence pertaining to the use of the void model in the selection of the cure cycle will be presented in the next section.

In the experiments, temperature distributions and resin flow perpendicular and parallel to the tool plate of unidirectional composites were measured. The experiments were performed using Hercules AS/3501-6 graphite fiber- 
reinforced, epoxy resin prepreg tape. The same cure temperature was used in every test. The cure temperatures on the lower and upper surfaces of the composite (as measured by thermocouples) are shown in Figure 7. The pressure was applied at the beginning of the cure cycle and remained constant for the duration of the cure. Tests were performed with different applied pressure ranging from $103 \mathrm{kPa}(15 \mathrm{psi})$ to $724 \mathrm{kPa}(105 \mathrm{psi})$. The pressure in the bleeder was taken to be equal to the ambient pressure of $101.35 \mathrm{kPa}(14.7$ psi).

The temperature as a function of time was measured at three locations inside a 64 ply composite. Results of the temperature measurements are presented in Figure 8.
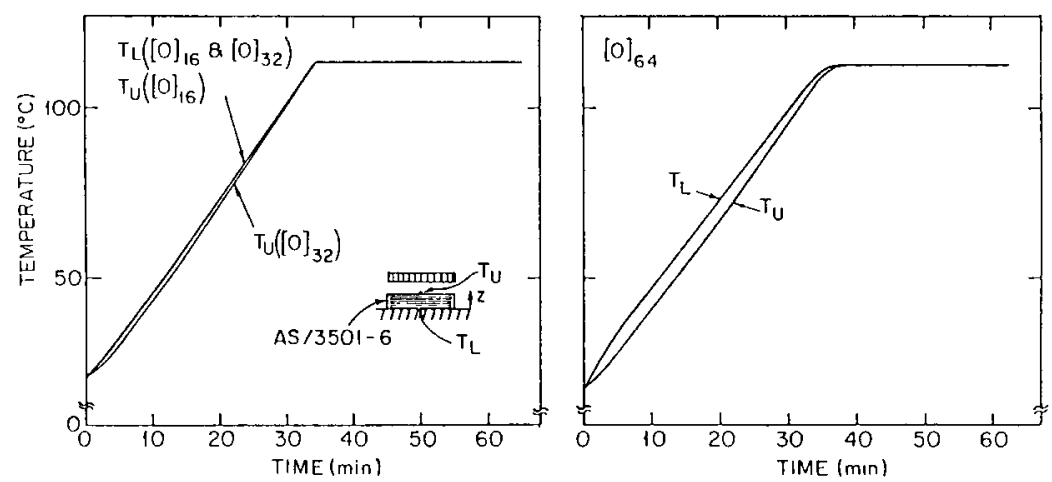

Figure 7. The temperatures measured on the surfaces of 16,32, and 64-ply composites during cure.

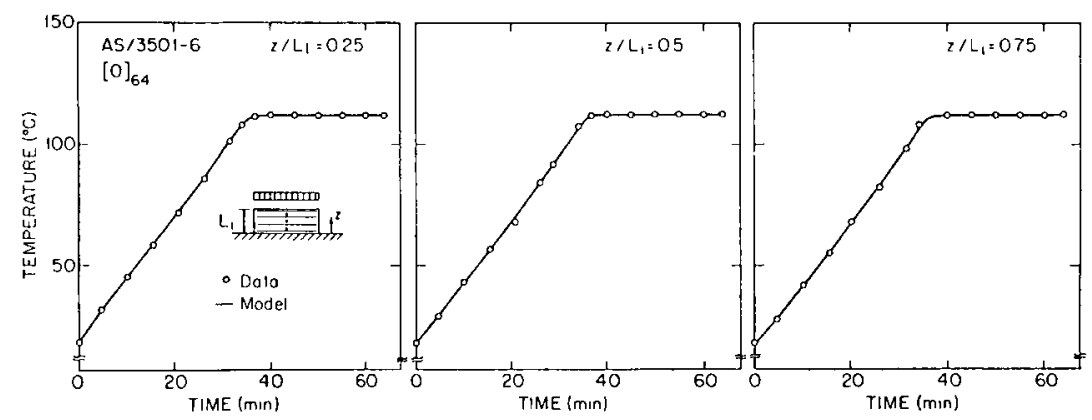

Figure 8. Temperature as a function of time at three positions inside a 64-p/y composite. Comparisons between the data and the results computed by the model. The temperature cure cycle is shown in Figure 15. The cure pressure and the bleeder pressure were constant at $586 \mathrm{kPa}$ (85 psi) and $101 \mathrm{kPa}(14.7$ psi) respectivehy. 
Resin flow measurements were made with different cure pressures $(103 \mathrm{kPa}$ (15 psi), $345 \mathrm{kPa}$ (50 psi), $586 \mathrm{kPa}(85 \mathrm{psi})$, and $724 \mathrm{kPa}$ (105 psi), different ply thicknesses $(16,32$, and 64 plies), and different initial prepreg resin contents $(39 \%$ and $42 \%)$. The results are shown in Figures 9-11. In these figures, time $t$ is plotted on the abscissa. The ordinates represent either the total mass loss $m^{*}$ of the composite or the mass losses due to resin flow in the directions normal $\left(m_{T}^{*}\right)$ and parallel $\left(m_{E}^{*}\right)$ to the tool plate in time $t$. The mass losses shown in Figures 9-11 represent the mass loss with respect to the initial mass of the composite

$$
m^{*}=\frac{\text { mass loss }}{\text { initial mass }} \times 100
$$

The temperature distribution in the composite and the resin flow were calculated by the models using the same cure temperatures and cure-pressures which were employed in the tests. The prepreg and bleeder properties used in the calculations are listed in Table 3.

The results of the models are represented by solid lines in Figures 8-11. As can be seen, the calculated and measured temperatures and the calculated and measured resin mass losses agree well. These agreements, which exist for wide ranges of applied cure pressures, composite thicknesses, and initial prepreg resin contents, tend to conform the validities of the thermo-chemical and resin flow models.
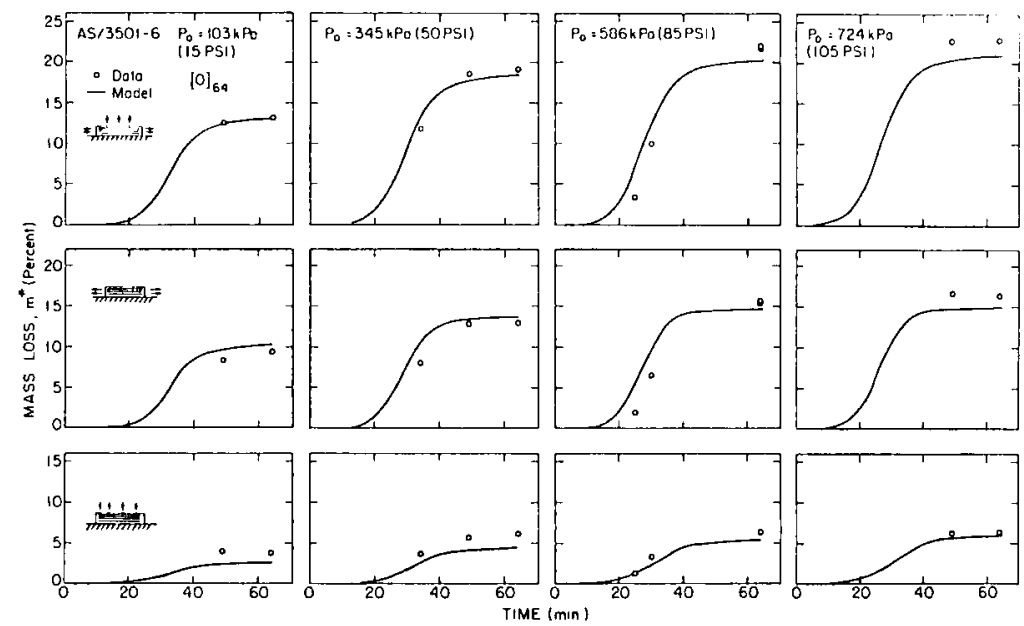

Figure 9. The mass loss, normal to the tool plate (bottom), parallel to the tool plate (center), and the total mass loss (top) as a function of time for a 64-ply composite. Comparisons between the data and the results computed by the model for different cure pressures. The temperature cure cycle is shown in Figure 15. The bleeder pressure was constant at $101 \mathrm{kPa}$ (14.7 psi). The initial resin content was $42 \%$. 


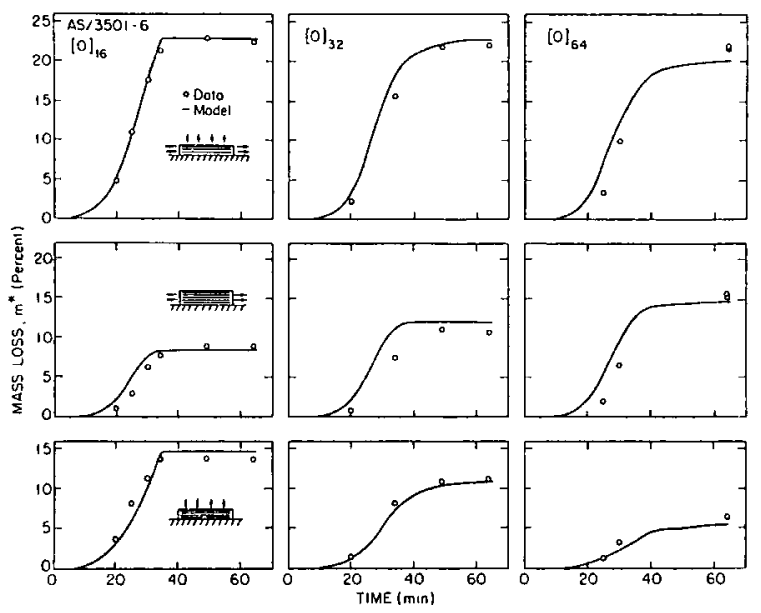

Figure 10. The mass loss, normal to the tool plate (bottom), parallel to the tool plate (center), and the total mass loss (top) as a function of time. Comparisons between the data and the results computed by the model for 16, 32, and 64-ply composites. The temperature cure cycle is shown in Figure 15. The cure and bleeder pressures were constant at $586 \mathrm{kPa}$ (85 psi) and $101 \mathrm{kPa}(14.7$ psi) respectively. The initial resin content was $42 \%$.

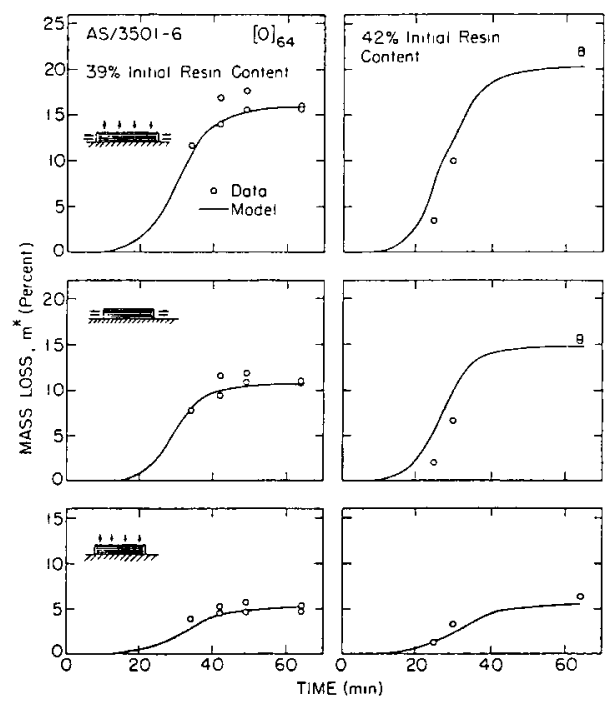

Figure 11. The mass loss, normal to the tool plate (bottom), parallel to the tool plate (center), and the total mass loss (top) as a function of time for a 64-ply composite. Comparisons between the data and the results computed by the model for different initial resin contents $139 \%$ and $42 \%)$. The temperature cure cycle is shown in Figure 15. The cure and bleeder pressures were constant at $586 \mathrm{kPa}(85 \mathrm{psi})$ and $101 \mathrm{kPa}(14.7$ psi) respectively. 


\section{SELECTION OF THE CURE CYCLE}

The models presented in this paper can be used to establish the proper cure cycle in a given application. The cure cycle should be selected in such a way that the following requirements are satisfied:

a) the temperature at any position inside the material does not exceed a prescribed limit during the cure;

b) the magnitude of the cure pressure is sufficiently high so that all of the excess resin is squeezed out from every ply of the composite before the resin gels at any point inside the composite;

c) the pressure is applied before the viscosity of the resin, in the prepreg ply adjacent to the bleeder, becomes low enough to flow;

d) the resin is cured uniformly and the degree of cure is above a specified limit throughout the composite at the end of cure;

e) the cured composite has a low void content; and

f) the composite is cured in the shortest time.

The models and the corresponding computer code were used to generate results which illustrate the effects of cure temperature and cure pressure on the curing process for a given material. The calculations were performed for composite made of Hercules AS/3501-6 prepreg tape, bounded by the tool plate on one side and by the bleeder on the other side. The properties used in the calculations are given in Table 3 . In the calculations, only resin flow in the

Table 3. Properties of Hercules AS/3501-6 Prepreg and Mochburg CW 1850 Thermal Fiber Bleeder Cloth used in the calculations.

\begin{tabular}{ll}
\hline AS/3601-6 & \\
Initial prepreg resin mass fraction & $42 \%$ \\
Initial thickness of the prepreg & $1.651 \times 10^{-} \mathrm{m}$ \\
Resin content of one compacted ply & $4.788 \times 10^{-2} \mathrm{~kg} / \mathrm{m}^{2}$ \\
Thickness of one compacted ply & $1.194 \times 10^{-4} \mathrm{~m}$ \\
Apparent permeability of the prepreg normal to the & $5.8 \times 10^{-16} \mathrm{~m}^{2}$ \\
$\quad$ plane of the composite & $1.7 \times 10^{2}$ \\
Flow coefficient of the prepreg parallel to the fibers & $1.26 \times 10^{3} \mathrm{~kg} / \mathrm{m}^{3}$ \\
Resin density & $1.26 \mathrm{~kJ} /(\mathrm{kg} \cdot \mathrm{K})$ \\
Specific heat of the resin & $1.67 \times 10^{-1} \mathrm{~W} /(\mathrm{m} \cdot \mathrm{K})$ \\
Thermal conductivity of the resin & $474 \mathrm{~J} / \mathrm{g}$ \\
Heat of reaction of the resin & $1.79 \times 10^{3} \mathrm{~kg} / \mathrm{m}^{3}$ \\
Fiber density & $7.12 \times 10^{-1} \mathrm{~kJ} /(\mathrm{kg} \cdot \mathrm{K})$ \\
Specific heat of the fiber & $2.60 \times 10^{1} \mathrm{~W} /(\mathrm{m} \cdot \mathrm{K})$ \\
Thermal conductivity of the fiber & \\
Relationship between the cure rate, temperature, and & $5 e e \mathrm{ref} .[4]$ \\
degree of cure & \\
Relationship between viscosity, temperature and & $5 e e \mathrm{ref} .[4]$ \\
degree of cure & \\
Mochburg Bleeder Cloth & $5.6 \times 10^{-11} \mathrm{~m}$ \\
Apparent permeability & 0.57 \\
\hline \begin{tabular}{l} 
Porosity \\
\hline
\end{tabular}
\end{tabular}


direction normal to the tool plate was considered. As was discussed previously, the dimensions of composite panels in commercial applications generally are such that resin flow along the plane of the composite is negligible.

The calculations were performed with the cure cycles shown in Figure 12. The cure temperature was increased at a constant heating rate $\dot{T}_{0}$ from room temperature until the maximum cure temperature $T_{\max }$ was reached. For all calculations, it was assumed that the temperature on the upper and lower surfaces of the composite was equal to the applied cure temperature.

The cure pressure and the bleeder pressure used in the calculations are also shown in Figure 12. The cure pressure was applied at the beginning of the curing process $\left(t_{p}=0\right)$ and remained constant for the duration of the cure. The magnitude of the cure pressure is indicated on each figure showing the results. The pressure in the bleeder was taken to be constant in $16.7 \mathrm{kPa}\left(25^{\prime \prime} \mathrm{Hg}\right.$ vacuum). This value is typical of the bleeder pressure in commercial composite processing using vacuum bagging procedures.

Calculations were also performed with the cure cycle recommended by the prepreg manufacturer for Hercules AS/3501-6 prepreg tape. This cycle is shown in Figure 13.

\section{Maximum Temperature Inside the Composite}

The maximum temperature reached inside a composite constructed from a given prepreg material depends on: a) the maximum value of the cure temperature $T_{\max }$, b) the heating rate $\dot{T}_{o}$ (i.e., the rate at which the cure temperature increases), and c) the thickness of the composite $L_{i}$. Obviously, the temperature inside the composite will at some time reach the maximum cure temperature. Therefore, the cure temperature must not exceed the maximum temperature limit $T^{*}$ prescribed for the prepreg. In the present parametric study, this limit was chosen arbitrarily to be $180^{\circ} \mathrm{C}$.

The temperature inside the composite also depends on the heating rate and
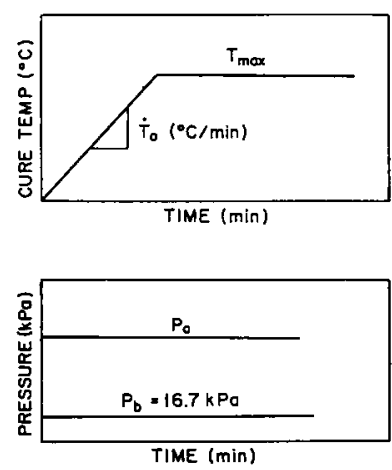

Figure 12. Illustration of the cure cycle used in the parametric study. 

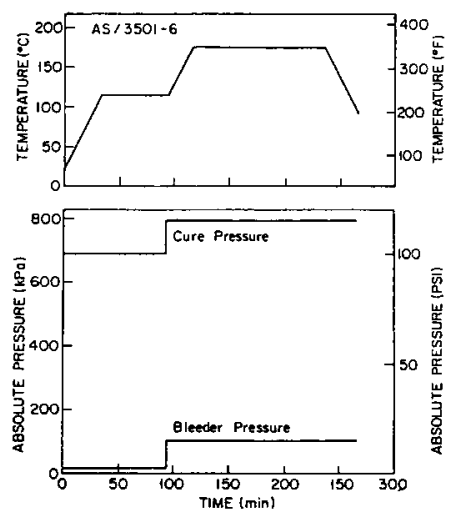

Figure 13. Manufacturer's recommended cure cycle for Hercules AS/3501-6 prepreg.

the thickness of the composite. At low heating rates, the temperature distribution inside the composite tends to remain uniform, as illustrated in Figure 14a. The results in this figure apply to a 64-ply composite with the cure temperature of $177^{\circ} \mathrm{C}$ at $2.8^{\circ} \mathrm{C} / \mathrm{min}$. When the heating rate was increased to $27.8^{\circ} \mathrm{C} / \mathrm{min}$, the temperature distribution became nonuniform, as shown in Figure 14b. However, at no time does the temperature at any place inside the composite exceed the maximum allowed temperature $T^{*}$. On the other hand, when a 128-ply composite was cured using the same heating rate $\left(27.8^{\circ} \mathrm{C} / \mathrm{min}\right)$, the temperature inside the material exceeded both the boundary temperature and the maximum allowed temperature limit (Figure 14c). The temperature nonuniformity inside the material depends on the rate at
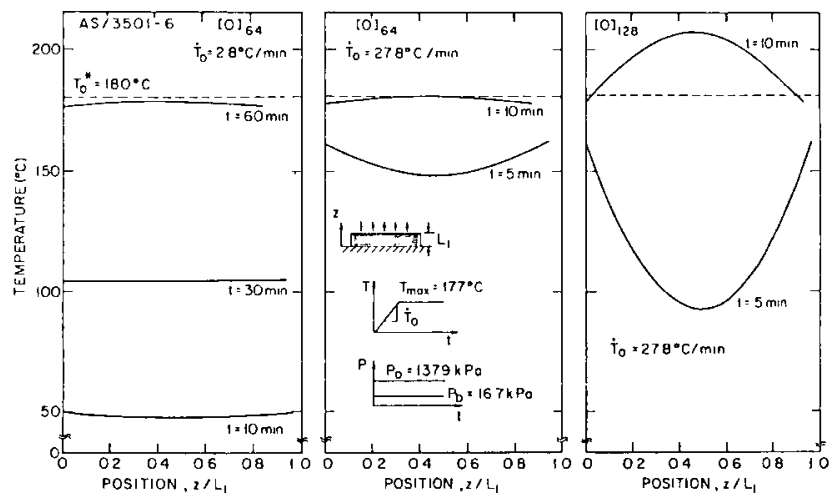

Figure 14. Temperature distribution as a function of time for different heating rates and different thicknesses. a) $64-p / y, T_{o}=2.8^{\circ} \mathrm{C} / \mathrm{min}\left((\mathrm{eft})\right.$, b) $64-\mathrm{p} / \mathrm{y}, \dot{T}_{o}=27.8^{\circ} \mathrm{C} / \mathrm{min}$ (center), and c) $128-p / y, T_{o}=27.8^{\circ} \mathrm{C} / \mathrm{min}$ (right). Results obtained by the model. 
which heat is transported through the composite and the rate at which heat is generated by chemical reactions. The temperature "overshoot" shown in Figure 14c occurs when heat is generated in the composite faster than it can be dissipated.

With the use of the computer code, results such as those in Figure 14 can be generated for a composite constructed from a given prepreg material and cured with a specified cure cycle. From these results, the temperature distribution inside the material can be established. This information can then be used to determine if the temperature distribution is uniform and if the local temperature at any point in the composite exceeds the maximum allowed temperature at any time.

\section{Resin Flow}

The pressure applied during the cure must be sufficiently high so that the excess resin is squeezed out of every ply of the composite before the resin in any ply gels. The magnitude of pressure applied when curing a given material depends on the composite thickness and, to a lesser extent, on the cure temperature and heating rate. This is illustrated in Figure 15, where the number of compacted plies $n_{s}$ is plotted as a function of time.

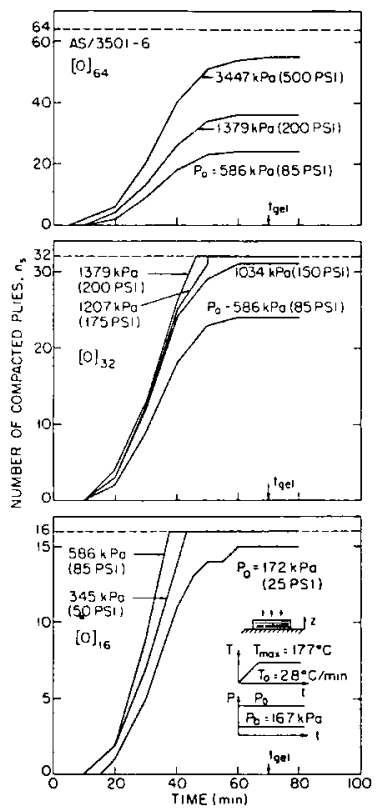

Figure 15. Number of compacted plies, $n_{s}$ as a function of time for different cure pressures and different composite thicknesses. a) 16-ply (bottom), b) 32-p/y (center), and c) 64-ply (top). Results obtained by the model. 
The curves in Figure 15 were generated by the computer code for different composite thicknesses $(16,32$, and 64 plies). Results of the calculations show that cure pressures of $345 \mathrm{kPa}$ (50 psi) and $1207 \mathrm{kPa}(175 \mathrm{psi})$ are sufficient to squeeze all the excess resin out of 16-ply and 32-ply composites, respectively, before the gel point is reached. However, for a 64-ply composite, an applied pressure of $3447 \mathrm{kPa}$ ( $500 \mathrm{psi}$ ) would squeeze excess resin out of only 55 plies, so that the 9 plies nearest to the tool plate would contain excess resin. These results apply to composites with a bleeder on one side only. If bleeders are placed on both sids of the composite and the same pressure is applied, excess resin can be squeezed out of approximately twice as many plies as with the single bleeder system.

For cure cycles employed in this parametric study, a change in the maximum cure temperature does not affect significantly the number of compacted plies (Figure 16a). Similarly, variations in the applied heating rates have little effect on the number of compacted plies, unless the heating rate is so large that the resin gels before the excess resin is squeezed out of every ply. For example, the results in Figure $16 \mathrm{~b}$ show that at a heating rate of $27.8^{\circ} \mathrm{C} / \mathrm{min}$, the resin gels at a time when only 30 plies are compacted in a 32-ply composite. Thus, excess resin remains in two plies.

Although the maximum cure temperature and the heating rate have little effect on the total number of compacted plies, these two parameters do affect the amount of time required to squeeze excess resin out of every ply in the composite, $t_{N}$. The effect of cure temperature and heating rate on the time required to squeeze excess resin out of every ply of a 32-ply composite is shown in Figure 17. The time required to squeeze the excess resin out of every ply in

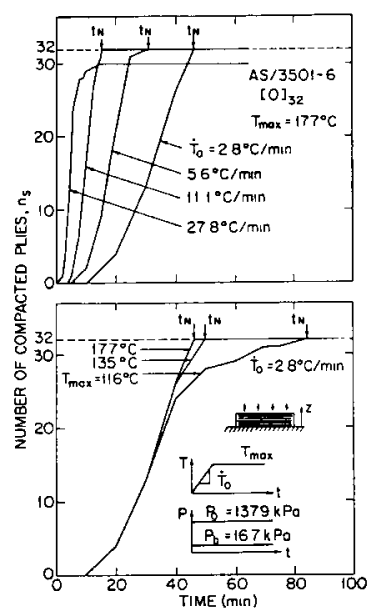

Figure 16. Number of compacted plies, $n_{s}$ as a function of time for al different maximum cure temperatures, $T_{\max }$ (bottom) and b) Different heating rates, $\dot{T}_{o}$ (top). Results obtained by the model. 

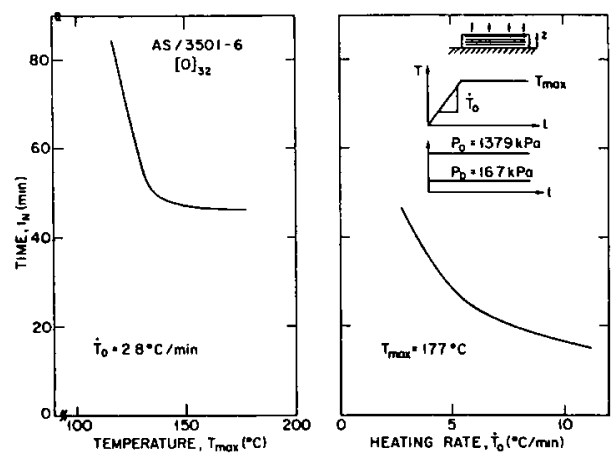

Figure 17. The time required, $t_{N}$ to squeeze excess resin out of every ply of a 32-p/y composite at a) different maximum cure temperatures, $T_{\max }\left(\right.$ left) and b) different heating rates, $\dot{T}_{o}$ (right). Results obtained by the model.

the composite decreases with increasing cure temperature and increasing heat rate.

Calculations were also performed for the cure cycle recommended by the manufacturer for processing composites made of Hercules AS/3501-6 prepreg (Figure 13). The number of compacted plies $n_{s}$ as a function of time is plotted in Figure 18. The results show that if the manufacturer's cure cycle is used, excess resin could be squeezed out from only a 23-ply composite before the gel point is reached. If composites thicker than 23 plies are cured with the manufacturer's recommended cure cycle, then there would be resin rich plies adjacent to the tool plate at the end of cure. There is experimental evidence that the manufacturer's recommended cure cycle may not be appropriate when curing thick composites. Meade [13] presented microphotographs of a 96-ply composite, constructed from Narmco T300/5208 unidirectional

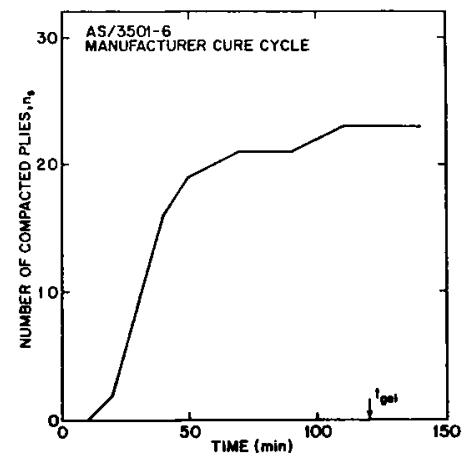

Figure 18. Number of compacted plies, $n_{s}$ as a function of time for a composite cured by the cure cycle recommended by the prepreg manufacturer (Figure 21). Results obtained by the model. 
prepreg tape, and cured with the manufacturer's recommended cure cycle. These microphotographs reveal the existence of uncompacted, resin-rich plies adjacent to the tool plate.

The foregoing results illustrate a procedure which can be used to determine if the excess resin is squeezed out of every ply in the composite before the gel point is reached. This procedure requires that for a given cure cycle, the number of compacted plies $n_{s}$ is calculated as a function of time. From a plot of $n_{s}$ versus time, it can readily be seen how many plies are compacted before the gel point is reached.

By performing the calculations for different cure pressures, the maximum number of plies that can be compacted $\left(n_{s}\right)_{\max }$ versus pressure for Hercules AS/3501-6 prepreg is given in Figure 19. Such a plot can serve as a guide in selecting the pressure which is sufficient to squeeze the excess resin out of every ply of a given composite.

\section{Gel Point}

As discussed previously, excess resin must be squeezed out of every ply before the gel point of the resin is reached at any point inside the composite. The computer code can be used to calculate the viscosity distribution inside the composite as a function of time (Figure 20). From this information, the maximum viscosity at any point inside the composite at any time can be determined and a plot of the maximum viscosity $\mu_{\max }$ versus time can be constructed (Figure 21). The gel point of the resin studied here is assumed to occur when the viscosity of the resin reaches 100 Pa.s $[14,15]$. Thus, by knowing the viscosity corresponding to the gel point, the time when gel occurs can be determined from the maximum viscosity $\mu_{\max }$ versus time curve, as shown in Figure 21.

The above procedure was used to determine the gel point of a 32-ply composite cured at $177^{\circ} \mathrm{C}$ with a cure pressure of $1379 \mathrm{kPa}(200 \mathrm{psi})$, as shown in

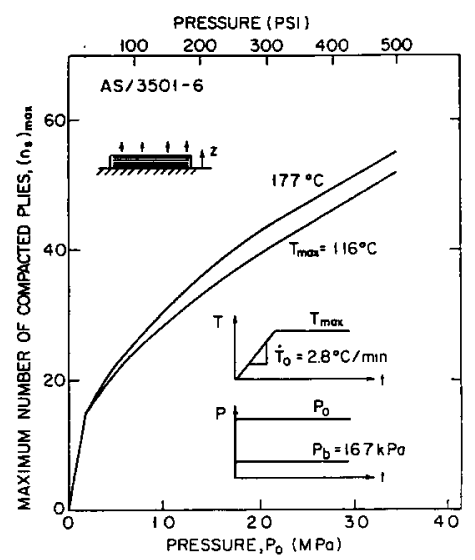

Figure 19. The maximum number of compacted plies, $\left(n_{s}\right)_{\text {max }}$ at the end of the cure as a function of cure pressure, $P_{o}$. Results obtained by the model. 


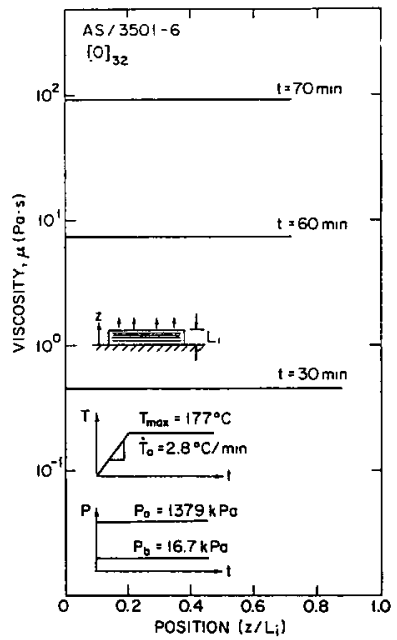

Figure 20. Viscosity distribution at different times inside a 32-ply composite. Results obtained by the model.

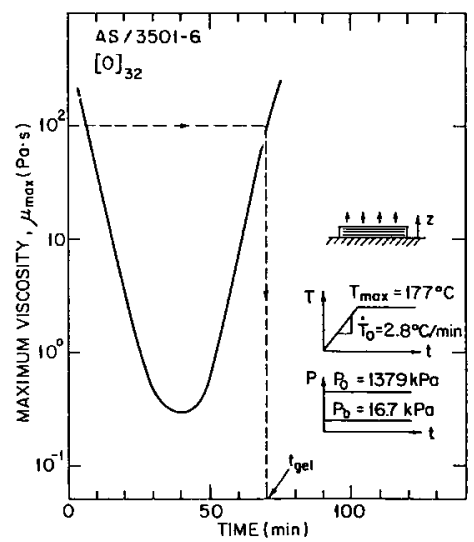

Figure 21. The maximum viscosity, $\mu_{\max }$ inside a 32-ply composite as a function of time. Gel is assumed to occur when the viscosity reaches 100 Pa.s. Results obtained by the model.

Figure 21. The intersection of the viscosity-time curve with the gel line (denoted as a dashed line on Figure 21) indicates that the resin would begin to gel in the composite 70 minutes after the cure temperature is first applied.

\section{Time of Pressure Application}

The cure pressure should be applied before the viscosity of the resin in the first ply next to the bleeder becomes sufficiently low for resin flow to occur. This is the latest time at which the pressure should be applied. This time, referred to as the time of pressure application $t_{p}$ can be determined from a 
plot of the number of compacted plies $n_{s}$ versus time, $t$. The intersection of the $n_{s}$ versus time curve with the time axis is taken to be time of pressure application (Figure 22).

The time of pressure application depends on the magnitude of the applied pressure and on the heating rate, as illustrated in Figure 22. The pressure may be applied, of course, at times which are less than $t_{p}$, but should not be applied at times greater than $t_{p}$. It should be emphasized that applying the cure pressure before $t_{p}$ does not ensure that all the excess resin will be squeezed out of every ply of the composite before the gel point is reached.

\section{Degree of Cure}

At the completion of the curing process, the resin in a composite should be cured uniformly, and the degree of cure must exceed a prescribed value $\alpha^{*}$ throughout the composite. The degree of cure will be uniform as long as the temperature distribution inside the composite is uniform, as illustrated in Figure 23a. Conversely, if the temperature distribution inside the composite
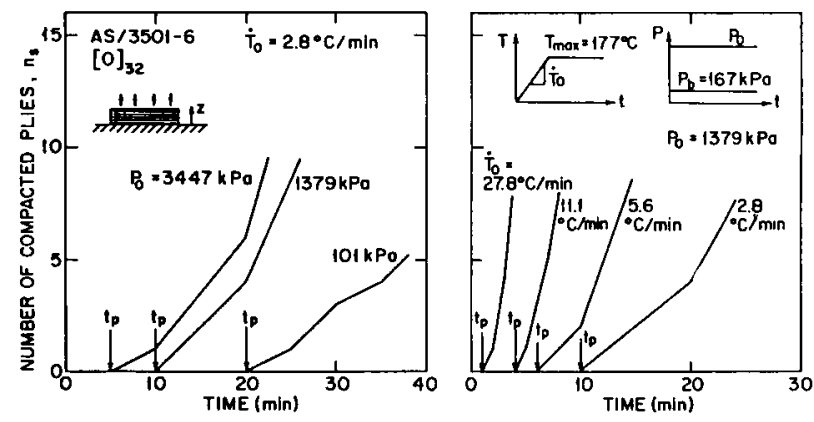

Figure 22. Number of compacted plies, $n_{s}$ as a function of time for al different cure pressures, $P_{o}$ (left) and $b$ ) different heating rates, $\dot{T}_{o}(r i g h t)$. The pressure should be applied before time $t_{p}$. Results obtained by the model.
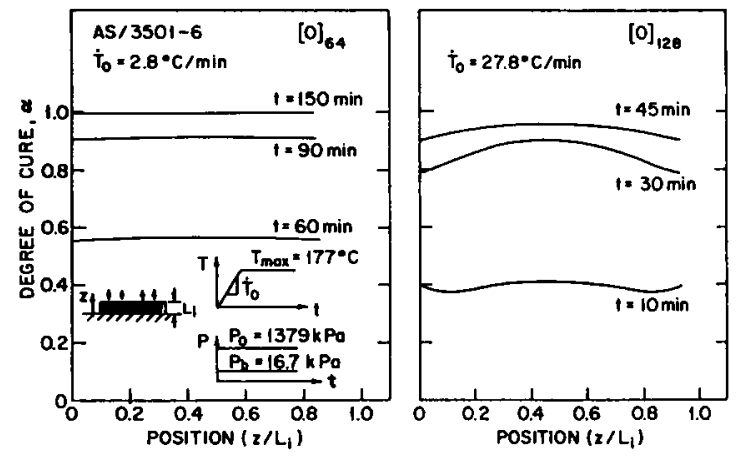

Figure 23. Degree of cure distribution as a function of time. a) 64-ply composite, $\dot{t}_{o}=2.8^{\circ} \mathrm{C} / \mathrm{min}$ (left). b) $128-\rho / y$ composite, $\dot{T}_{o}=27.8^{\circ} \mathrm{C} / \mathrm{min}$ (right). Results obtained by the model. 
becomes nonuniform, the degree of cure can also be expected to be nonuniform, as shown in Figure 23b. Therefore, cure cycles which result in uniform temperature distributions also result in composites that are cured uniformly.

The computer code can be used to generate results such as those shown in Figure 23. From these results, the degree of cure as a function of position inside the composite can be determined. Once this information is known, it can be determined if the composite was cured uniformly and if the degree of cure exceeds the prescribed value of $\alpha^{*}$ throughout the composite.

\section{Cure Time}

When curing a composite, it is desirable that the curing process be completed in the shortest amount of time. The cure is considered complete when the degree of cure reaches a specified value $\alpha^{*}$ at every point in the composite. The time required to reach this value can be established by first plotting the degree of cure as a function of position and time, as shown in Figure 23. From this curve, the lowest value of the degree of cure $\alpha_{\min }$ in the composite at each time is determined and a plot of the lowest value of the degree of cure as a function of time can be constructed (Figure 24). The cure is considered complete when $\alpha_{\min }$ reaches the specified value $\alpha^{*}$. Thus, from a plot such as that shown in Figure 25, the time required to complete the curing process can be determined.

The cure time $t_{c}$ depends greatly on the applied cure temperature and on the heating rate, as illustrated in Figure 25. The results in these figures are based on the assumption that cure is complete when a degree of cure of 0.9 is

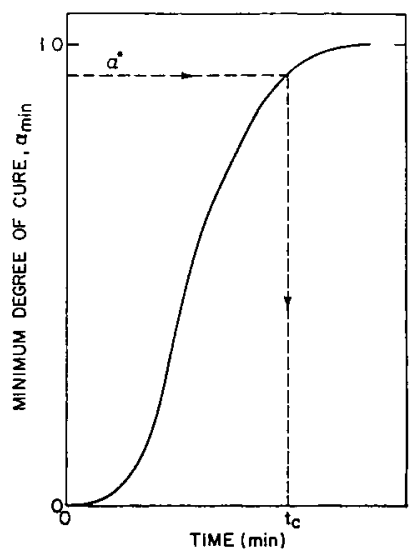

Figure 24. Illustration of the minimum value of the degree of cure, $\alpha_{\text {min }}$ inside the composite as a function of time. The cure is considered complete when the degree of cure reaches a specified value, $\alpha^{*}$, at every point in the composite. 


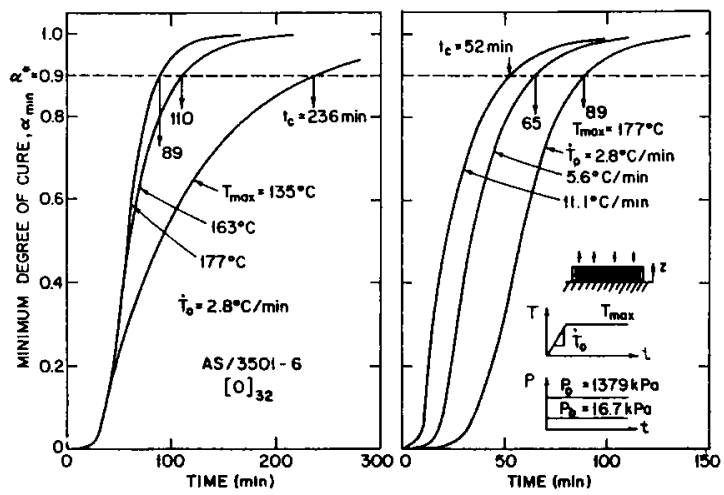

Figure 25. Minimum degree of cure, $\alpha_{\text {mir }}$ as a function of time for a 32-ply composite at al different maximum cure temperatures, $T_{\max }\left(\right.$ left) and b) different heating rates, $\dot{T}_{o}$ (right). Results obtained by the model.

reached at all points of the composite. For example, a 32-ply composite constructed from Hercules AS/3501-6 prepreg and cured using a heating rate of $2.8^{\circ} \mathrm{C} / \mathrm{min}$ and a maximum cure temperature of $177^{\circ} \mathrm{C}$, requires a cure time of 89 minutes (Figure 25a). If the maximum cure temperature is reduced to $135^{\circ} \mathrm{C}$, the calculated cure time increases to 236 minutes.

The effect of heating rate on the cure time is illustrated in Figure 25b. Increasing the heating rate of a 32-ply composite (maximum cure temperature $177^{\circ} \mathrm{C}$ ) from $2.8^{\circ} \mathrm{C} / \mathrm{min}$ to $11.1^{\circ} \mathrm{C} / \mathrm{min}$ results in a 37 minute reduction in cure time (Figure 25b).

The computer code can be used to calculate the cure time for different maximum cure temperatures and heating rates. A plot of cure time versus cure temperature, and a plot of cure time versus heating rate for Hercules AS/3501-6 prepreg is given in Figure 26. Results such as those shown in

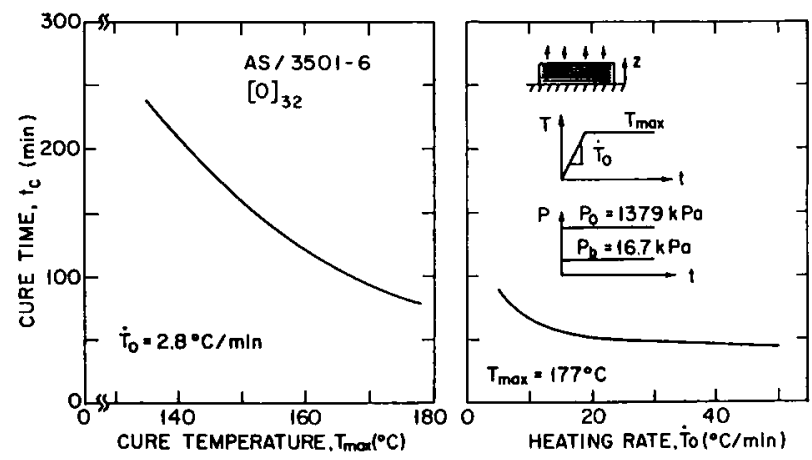

Figure 26. Cure time, $t_{c}$ as a function of a) maximum cure temperature, $T_{\max }($ left) and b) heating rate, $\dot{T}_{o}$ (right), for a 32-ply composite. Results obtained by the model. 
Figure 26 can be used to estimate the required cure time for a composite cured with a specified temperature cure cycle.

It is interesting to note that a 32-ply composite cured with the manufacturers recommended cure cycle requires a cure time of 146 minutes (Figure 27). Thus, use of the $177^{\circ} \mathrm{C}$ cure cycle with a heating rate of $2.8^{\circ} \mathrm{C} / \mathrm{min}$ (Figure 25a) would result in a 57 minute (37\%) savings in cure time. These results show that significant savings in cure time might be achieved by careful selection of the cure cycle.

\section{Void Model}

The void model requires that both the location and the initial size of the void be known. This information is generally unavailable, because the formation of the void nuclei is a random process. Nevertheless, the model can still be used in selecting a cure cycle which results in low void content.

It has been observed that the void content is reduced significantly when a pressure is applied to the prepreg which is sufficiently high to collapse the vapor bubble [16]. Thus, the vapor bubbles can be collapsed by applying a pressure (just before the gel point is reached, $t<t_{\text {gel }}$ ) which is equal to or higher than the saturation pressure (corresponding to the local temperature) inside the void. The thermo-chemical and resin flow models provide the temperature and the gel time. The appropriate thermodynamic relationship between the temperature and the saturation pressure yields the required pressure. Such a relationship for water vapor is incorporated in the CURE computer code.

\section{SUMMARY}

The following major tasks were completed during the course of this investigation

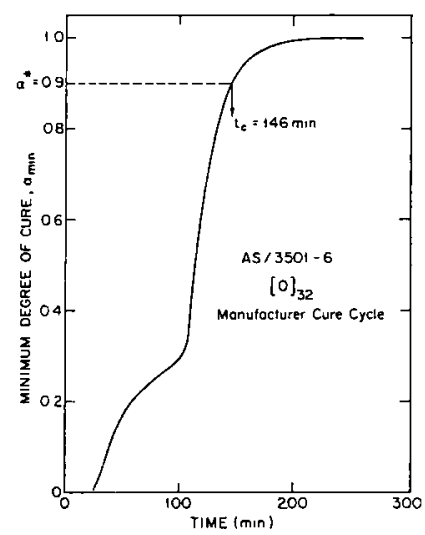

Figure 27. Minimum degree of cure, $\alpha_{\text {min, }}$ as a function of time for a 32-ply composite cured by the manufacturer's recommended cure cycle (Figure 21). Results obtained by the model. 
1) Models are described which simulate the curing process of composites constructed from continuous fiber-reinforced, thermosetting resin matrix prepreg materials. The models relate the cure cycle to the thermal, chemical, and physical processes occurring in the composite during cure.

2) On the basis of the models, a computer code ("CURE") was developed which can be used to generate the following information for flat plate composites cured by a specified cure cycle:

a) the temperature inside the composite as a function of position and time;

b) the degree of cure of the resin, as a function of position and time;

c) the resin viscosity, as a function of position and time;

d) the number of compacted prepreg plies as a function of time;

e) the amount of resin in the bleeder as a function of time;

f) the thickness and the mass of the composite as a function of time;

g) the void sizes and temperatures and pressures inside the voids as functions of void location and time; and

h) the residual stress distribution inside the composite after the cure.

3) The input parameters required in the computer code for the solution of the models were specified. The methods used to determine the parameters generally not known were described.

4) Experiments were performed measuring the temperature distribution in and the resin flow out of composites during cure, using test specimens constructed from Hercules AS/3501-6 prepreg material.

5) Calculations were performed with the computer code for the conditions employed in the experiments. The calculated results were compared with the experimental data and the results of the computer code showed that the model describes adequately the temperature distribution and resin flow.

6) A parametric study was performed to illustrate how the model and the associated computer code can be used to determine the appropriate cure cycle for a given application which results in a composite that is cured uniformly, has a low void content, and is cured in the shortest amount of time.

\section{ACKNOWLEDGMENT}

This work was supported by the U.S. Air Force Systems Command, Materials Laboratory, Wright Patterson Air Force Base, Dayton Ohio, with Dr. S. W. Tsai acting as project engineer.

\section{REFERENCES}

1. Springer, G. S., "A Model of the Curing Process of Epoxy Matrix Composites," in Progress in Science and Engineering of Composites, (T. Hayashi and K. Kawaka, eds.) Japan Society of Composite Materials, pp. 23-35 (1982).

2. Springer, G. S., "Resin Flow During the Cure of Fiber Reinforced Composites," Journal of Composite Materials, Vol. 16, pp. 400-410, (1982). 
3. Loos, A. C. and Springer, G. S., "Calculation of Cure Process Variables During Cure of Graphite-Epoxy Composites," in Composite Materials, Quality Assurance and Processing, (C. E. Browning, ed.) ASTM STP 797, pp. 110-118, (1983).

4. Lee, W. I., Loos, A. C. and Springer, G. S., "Heat of Reaction, Degree of Cure, and Viscosity of Hercules 3501-6 Resin," Journal of Composite Materials, Vol. 16, pp. 510-520, (1982).

5. Loos, A. C. and Springer, G. S., "Curing of Graphite/Epoxy Composites," Air Force Materials Laboratory Report AFWAL-TR-83-4040 Wright Aeronautical Laboratories, Wright Patterson Air Force Base, Dayton, OH. (1983).

6. Springer, G. S. and Tsai, S. W., "Thermal Conductivities of Unidirectional Materials," Journal of Composite Materials, Vol. 1, pp. 166-173 (1967).

7. Bartlett, C. J., "Use of the Parallel Plate Plastometer to Characterize Glass-Reinforced Resins: I. Flow Model," SPE Technical Papers, Vol. 24, pp. 638-640 (1978).

8. White, F. M., "Viscous Fluid Flow," McGraw-Hill, New York (1974) pp. 336-337.

9. Kardos, J. L., Dudukovic, J. P., McKague, E. L., and Lehman, M. W., "Void Formation and Transport during Composite Laminate Processing," in Composite Materials, Quality Assurance and Processing (C. E. Browning, ed.), ASTM STP 797, pp. 96-109, (1983).

10. Springer, G. S., "Environmental Effects on Composite Materials," Technomic Publishing Co. (1981).

11. Tsai, S. W. and Hahn, H. T., "Introduction to Composite Materials," Technomic Publishing Co. (1980).

12. Jones, R. M., "Mechanics of Composite Materials," McGraw-Hill (1980).

13. Meade, L. E., "Fabrication of Thick Graphite/Epoxy Wing Surface Structure," in Proceedings of the 24th National SAMPE Symposium and Exhibition, San Francisco, CA. (May 8-10, 1979), Vol. 24, Book 1, pp. 252-259.

14. Hollands, K. M. and Kalnin, I. L., "The Kinetics of Gelation of Some Accelerated Acid Anhydride Cure Epoxy Resin," in Epoxy Resins, Advances in Chemistry Series No. 92, American Chemical Society, Washington, D.C. (1970) pp. 60-69.

15. Roller, M. B., "Characterization of the Time-Temperature-Viscosity Behavior of Curing B-Staged Epoxy Resin," Polymer Engineering and Science, Vol. 15, pp. 406-414 (1975).

16. Brown, G. G. and McKague, E. L., "Processing Science of Epoxy Resin Composites," Technical Orientation, General Dynamics, Convair Division, San Diego, CA. (August 1982). 